\title{
Acromegaly pathogenesis and treatment
}

\author{
Shlomo Melmed
}

\author{
Department of Medicine, Cedars-Sinai Medical Center, Los Angeles, California, USA
}

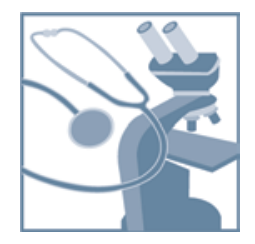

Dysregulated growth hormone (GH) hypersecretion is usually caused by a GH-secreting pituitary adenoma and leads to acromegaly - a disorder of disproportionate skeletal, tissue, and organ growth. High GH and IGF1 levels lead to comorbidities including arthritis, facial changes, prognathism, and glucose intolerance. If the condition is untreated, enhanced mortality due to cardiovascular, cerebrovascular, and pulmonary dysfunction is associated with a $30 \%$ decrease in life span. This Review discusses acromegaly pathogenesis and management options. The latter include surgery, radiation, and use of novel medications. Somatostatin receptor (SSTR) ligands inhibit GH release, control tumor growth, and attenuate peripheral GH action, while GH receptor antagonists block $\mathrm{GH}$ action and effectively lower IGF1 levels. Novel peptides, including SSTR ligands, exhibiting polyreceptor subtype affinities and chimeric dopaminergic-somatostatinergic properties are currently in clinical trials. Effective control of GH and IGF1 hypersecretion and ablation or stabilization of the pituitary tumor mass lead to improved comorbidities and lowering of mortality rates for this hormonal disorder.

Acromegaly is a disorder of disproportionate skeletal, tissue, and organ growth and occurs with an annual incidence of approximately five cases per one million individuals. Although the disorder has been recognized since antiquity, the pathology of pituitary "prosopectasia" was first described by Andrea Verga in 1864 and the clinical features of acromegaly by Pierre Marie in 1886. Disease pathogenesis involves growth hormone $(\mathrm{GH})$ hypersecretion by tumorous pituitary somatotroph cells, and the diagnosis is invariably preceded by about 10 years of active but unrecognized disease (1-3). Clinical presentation of acromegaly, in descending frequency as determined in a study of approximately 600 patients, includes acral and facial changes, hyperhidrosis (abnormally increased perspiration), headaches, paresthesia ("pins and needles" tingling sensation), sexual dysfunction, hypertension, goiter, and rarely, visual field defects (4) (see Sidebar 1). Subtle skeletal and acral overgrowth and soft tissue enlargement may occur inexorably over years (refs. 4, 5, S1; supplemental material available online with this article; doi:10.1172/JCI39375DS1), with frontal skull bossing (resulting in an unusually prominent forehead and heavy brow ridge), mandibular prognathism (protruding lower jaw), jaw malocclusion and overbite, skin thickening, and increased shoe and ring size (Figure 1). Chronic exposure to GH and IGF1 hypersecretion leads to soft tissue swelling of tongue, heart, kidney, colon, and vocal cords and periarticular and cartilaginous thickening, resulting ultimately in painful large-joint osteoarthritis. Up to $60 \%$ of patients exhibit spinal kyphoscoliosis (outward curvature of the spine) and diffuse skeletal hyperostosis (overgrowth of bone). Disease duration, IGF1 levels, and concurrent hypogonadism determine the prevalence of vertebral fractures (S2). Elevated levels of the hormone prolactin (PRL), observed in approximately $30 \%$ of patients, can be ascribed to mixed tumor GH and PRL cosecretion or to pituitary stalk impingement by the tumor mass. Rarely, plurihormonal tumors cosecrete the thyroid-stimulating hormone thyrotropin (TSH), leading to hyperthyroxinemia (elevated circulating thyroxine levels), or adrenocorticotropin (ACTH), leading to hypercortisolemia (elevated circulating cortisol levels).

Conflict of interest: The author receives preclinical research grant support from Novartis and is a research consultant for Ipsen.

Citation for this article: J. Clin. Invest. 119:3189-3202 (2009). doi:10.1172/JCI39375.
This article reviews recent scientific discoveries that have had an impact on our understanding of acromegaly pathogenesis and clinical features. Novel approved and experimental therapies have evolved from these fundamental insights and are discussed in the context of providing added benefit to patient care and disease control.

\section{Diagnosis}

The diagnosis of acromegaly requires demonstration of dysregulated and enhanced GH secretion as well as elevated IGF1 levels, reflective of peripheral tissue exposure to tonically elevated GH concentrations (6). In acromegaly, basal GH secretion is tonically elevated with relatively blunted bursts (Figure 2). Accordingly, a random $\mathrm{GH}$ value of less than $0.04 \mu \mathrm{g} / \mathrm{l}$ effectively excludes the diagnosis of acromegaly. Importantly, an elevated randomly obtained GH measurement may not necessarily imply excessive integrated GH secretion. Net GH secretion is attenuated after age 60 (when 24-hour GH secretion is less than $50 \%$ of that in younger subjects) and by elevated BMI.

Older $\mathrm{GH}$ radioimmunoassays were relatively insensitive and poorly reproducible. Newer immunoradiometric assays and immunoluminometric assays are based on the use of two-site monoclonal antibodies, and although they detect GH concentrations of less than $0.05 \mu \mathrm{g} / \mathrm{l}$, these assays are beset by challenges of reproducibility. Lack of universal standards, nonuniform antibody recognition of GH isoforms, and the presence of circulating GH-binding proteins contribute to method-dependent and patient-specific variability of GH measurements. In a multicenter study of GH nadir after an oral glucose tolerance test (OGTT), reference ranges varied by approximately $50 \%$, and $30 \%$ of obtained results were inconsistent with the correct diagnosis (7). There is a compelling need for reliable $\mathrm{GH}$ assays based on robust reference standards.

A functional hallmark of a GH-secreting pituitary adenoma is the inability to respond appropriately to a glucose-induced neuroendocrine suppressive signal. The inability to suppress GH secretion to less than $1 \mu \mathrm{g} / \mathrm{l}$ during 2 hours after an oral glucose load (75 grams) is the current consensus for diagnosing acromegaly (8). However, this cutoff may in fact be insensitive, and patients have been identified with clinical features of acromegaly, elevated IGF1 levels, and nadir postglucose GH levels of less than $1 \mu \mathrm{g} / 1$ (9). Using ultrasensitive GH assays, a nadir GH cutoff of less than 


\section{Sidebar 1}

Impact of long-term GH and IGF1 exposure

$\begin{array}{ll}\text { Organ/tissue } & \text { Clinical feature } \\ \text { Bone and joint } & \text { Acral changes, gigantism, prognathism, arthritis, osteopenia, vertebral fractures, carpal tunnel syndrome } \\ \text { Heart } & \text { Cardiomyopathy, hypertension, arrhythmias, valvulopathy, heart failure } \\ \text { Skin } & \text { Tags, excessive oily perspiration } \\ \text { Pancreas } & \text { Insulin resistance, diabetes } \\ \text { Lung } & \text { Obstructive sleep apnea } \\ \text { Kidney } & \text { Antinatriuresis, fluid retention, increased aldosterone, renal failure } \\ \text { Gonads } & \text { Hypogonadism } \\ \text { Thyroid } & \text { Goiter } \\ \text { Muscle } & \text { Proximal myopathy } \\ \text { Colon } & \text { Polyps } \\ \text { Fat } & \text { Lipolysis } \\ \text { Visceromegaly } & \text { Tongue, thyroid, salivary gland, liver, spleen, kidney, prostate }\end{array}$

$0.3 \mu \mathrm{g} / \mathrm{l}$ is effectively more discriminatory. Failure to suppress $\mathrm{GH}$ levels may also be encountered in patients with diabetes, renal or hepatic failure, and obesity or those receiving estrogen replacement or who are pregnant.

Screening of IGF1 levels is useful in obtaining a surrogate reflection of integrated GH secretion. IGF1 levels are relatively stable, correlate with clinical features of acromegaly (10), and exhibit a log-linear relationship with elevated GH levels (S3). Measured circulating IGF1 concentrations plateau when GH levels are greater than $20 \mu \mathrm{g} / \mathrm{l}$, and subtle GH elevations do not uniformly induce IGF1. Accurate IGF1 evaluation requires age-matched control values, especially as levels decrease about $14 \%$ per decade with aging (11). Malnourished patients and those with liver and renal failure or those receiving estrogen exhibit lower IGF1 levels. The importance of appropriate age-adjusted normal IGF1 values was highlighted in a recent study using 4 different assays in 40 acromegaly patients; result variances were minimized with increased numbers of appropriately matched controls (12). Importantly, robust IGF1 assays may exhibit up to $30 \%$ within-subject variance in healthy subjects (13).

\section{Morbidity impact of exposure to excess GH/IGF1}

\section{Mortality determinants}

Large retrospective studies of acromegaly patients (14) indicate an average 10-year reduction in life expectancy, with at least a doubling of standardized mortality rates (SMRs) due to cardiovascular, cerebrovascular, metabolic, and respiratory comorbidities. Mean weighted SMRs in treated patients were $1.72(1.62-1.83,95 \% \mathrm{CI})$, with earlier studies showing higher ratios (15). Overall, achieving a posttreatment $\mathrm{GH}$ level of less than $2.5 \mu \mathrm{g} / 1$ results in maintaining normal life expectancy rates $(2,15)$. Independent survival determinants include the last recorded GH level $(P<0.001)$, hypertension $(P<0.02)$, heart disease $(P<0.03)$, and disease duration $(P<0.04)(14)$. In an outcomes study of 419 patients, cerebrovascular SMRs were elevated at $2.68(1.73-4.15, P<0.007)$, while malignancy-associated mortality was not enhanced (16). These results likely reflect the positive impact of recent multimodal therapy on mortality outcomes.

Radiotherapy directed at the GH-secreting pituitary adenoma may also be associated with increased mortality $(P<0.005)(16)$, especially from cerebrovascular disease. Although overall cancer incidence is not enhanced, there is a moderate risk of develop- ing colorectal cancer (S4). Uncontrolled GH levels likely provide a growth advantage to neoplasms, resulting in more aggressive disease and increased cancer-associated mortality. Colonoscopy shows increased colon length and mucosal hypertrophy; up to $25 \%$ of polyps are right-sided and recur within 3 years.

A potential determinant of acromegaly mortality could be iatrogenic or endogenous hypopituitarism (failure of the pituitary gland to produce normal amounts of one or more of its hormones), resulting in deficiencies of pituitary-target hormone axes. Ideally, achievement of rigorously controlled GH and IGF1 levels would be expected to normalize SMRs. Accordingly, comorbidities associated with musculoskeletal degeneration and disfigurement, large organ hyperplasia, and cardiac and vascular dysfunction remain as therapeutic challenges.

\section{Comorbidities}

The constellation of hypertension, cardiac arrhythmias, glucose intolerance, and diastolic dysfunction leads to heart failure, which may be intractable, especially if GH levels remain uncontrolled. Biventricular cardiac hypertrophy manifests early in response to elevated GH levels and is present in $20 \%$ of young acromegaly patients and in up to $90 \%$ of patients with long-standing disease independent of the presence of hypertension. Postexercise ventricular ejection fraction is increased in approximately $70 \%$ of patients (17), and approximately 50\% are at intermediate-to-high risk for coronary arteriosclerosis (S5). The pathogenesis of hypertension is associated with plasma volume expansion and increased cardiac output (18). Although hypertension has been ascribed to increased peripheral vascular resistance, vessel growth and intimal thickness are not uniformly dysregulated. GH exerts antinatriuretic effects, leading to increased extracellular volume, soft tissue swelling, and organomegaly. GH acts at the aldosterone-sensitive distal nephron, and transepithelial sodium transport is attenuated by a $\mathrm{GH}$ receptor (GHR) antagonist, while cortical collecting duct epithelial sodium channel subunit transcription is induced by GH (19). Insulin resistance caused by GH excess results in glucose intolerance and diabetes (5), further exacerbating renal dysfunction.

Airway obstruction consequent to macroglossia (tongue enlargement) and hypertrophy of laryngeal and pharyngeal mucosal tissues lead to upper airway obstruction, hypoventilation, snoring, and sleep apnea in approximately $50 \%$ of patients (S6). 
A

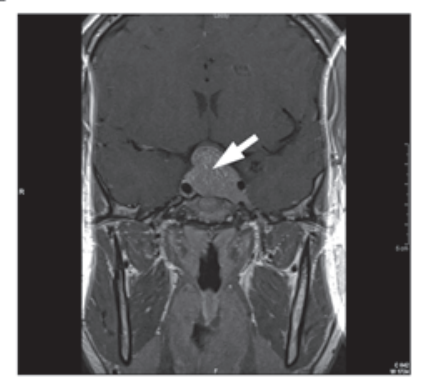

E
B

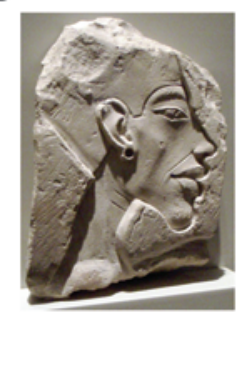

C

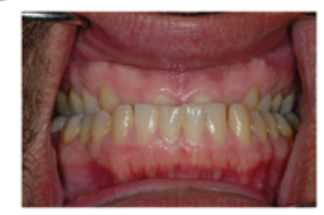

D

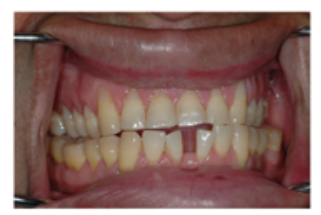

F

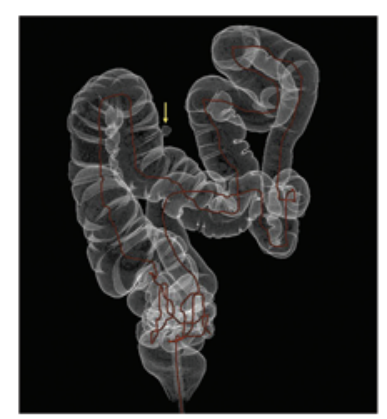

\section{Figure 1}

Impact of long-term GH and IGFI exposure. (A) MRI of GH-secreting pituitary macroadenoma depicting lateral tumor extension into cavernous sinus and dorsal elevation of optic chiasm (coronal image). (B) Image of limestone relief portrait of Egyptian Akhenaten, circa 1365 BCE, showing jaw prognathism and thickened lips. Reproduced with permission from Wikipedia (http://commons.wikimedia.org/wiki/File:ReliefPortraitOfAkhenaten01.png). Source: Altes Museum, Berlin, Germany. (C) Jaw prognathism and mandibular overbite and (D) widened incisor tooth gap in two acromegaly patients. (E) Governor Pio Pico of California in 1858. Note acromegaly facial features and mild left proptosis consistent with cavernous sinus tumor invasion. Reproduced with permission from Pituitary (S40). (F) Dolicomegacolon in acromegaly as visualized by CT colonography. The colonic centerline (red) is visible. Yellow arrow indicates a diverticulum of the transverse colon. Reproduced with permission from the Journal of clinical endocrinology and metabolism (125).

\section{GH secretion and action}

Anterior pituitary development follows highly specialized precursor stem cell commitment, with restricted differentiation of hormone-secreting cell types. Somatotrophs account for more than $50 \%$ of pituitary hormone-secreting cells, and transcription factors paired-like homeodomain factor 1 (PROP1) and POU class 1 homeobox 1 (POU1F1) determine cell differentiation and commitment to synthesizing and secreting $\mathrm{GH}(20,21)$. A family of genes located on the long arm of chromosome 17 encodes the GH peptides, encompassing pituitary human $\mathrm{GH}$, a placental variant of human GH (hGH) known as hGH-V, placental lactogen, and PRL (22). An alternatively spliced pituitary GH molecule is devoid of aa $32-46$ and is designated as $20-\mathrm{kDa}$ GH. Structural characteristics of the 191-aa GH molecule that are important for peptide function include the third $\alpha$-helix, comprising amphiphilic domain elements important for signaling, and integrity of the large helical loop is required for growth-promoting actions (23). GH mediates linear skeletal growth and also regulates carbohydrate, lipid, and mineral metabolism (24). Most of the growth-promoting actions of GH are enabled by IGF1.

Hypothalamic GH-releasing hormone (GHRH), ghrelin (mainly gut-derived), and somatostatin (SRIF) traverse the pituitary portal system to regulate $\mathrm{GH}$ production by anterior pituitary somatotroph cells (25) (Figure 2). GHRH, acting via the GHRH G protein-coupled receptor, induces and maintains somatotroph trophic function and induces $G H$ gene transcription and secretion (26). Ghrelin, a gut-derived GH secretagogue (27), acts mainly at the hypothalamus and signals through the ghrelin secretagogue receptor type Ia (GHS-RIa) to induce GH secretion in synergy with GHRH (S7). GHRH also signals via the ghrelin receptor (28), acting as an allosteric coagonist for the GHS-RIa. GHRH and ghrelin thus act coordinately to regulate pituitary function as well as energy homeostasis. SRIF, acting via pituitary $\mathrm{SSTR}_{2}$ (where SSTR denotes SRIF receptor subtype) and $\mathrm{SSTR}_{5}$ subtypes, attenuates both the timing and amplitude of GH secretory pulses. GH secretion is characterized by sporadic secretory pulses interspersed with mostly minimal basal secretion determined by age, sex, specific nutrients, neurotransmitters, exercise, and stress. Random daytime GH measurements are usually very low for approximately $80 \%$ of the day and may range from undetectable to secretory peaks of up to $15 \mu \mathrm{g} / \mathrm{l}$ or higher in normal subjects, observed mainly at night. Increased BMI and obesity attenuate GH secretion, while malnutrition and prolonged fasting result in elevated GH pulse frequency and amplitude (29).

\section{GH signaling}

The gene encoding the GHR, a class I pleiotropic cytokine receptor (30), is ubiquitously expressed, especially in liver, fat, and muscle. The GH molecule interacts with a preformed dimer of identical GHR pairs, which undergoes rotation and triggers ligand-receptor complex signaling (31) (Figure 3). As a consequence, two JAK2 molecules undergo autophosphorylation and also phosphorylate the GHR cytoplasmic domain (S8). Subsequent JAK2-dependent and -independent intracellular signal transduction pathways 


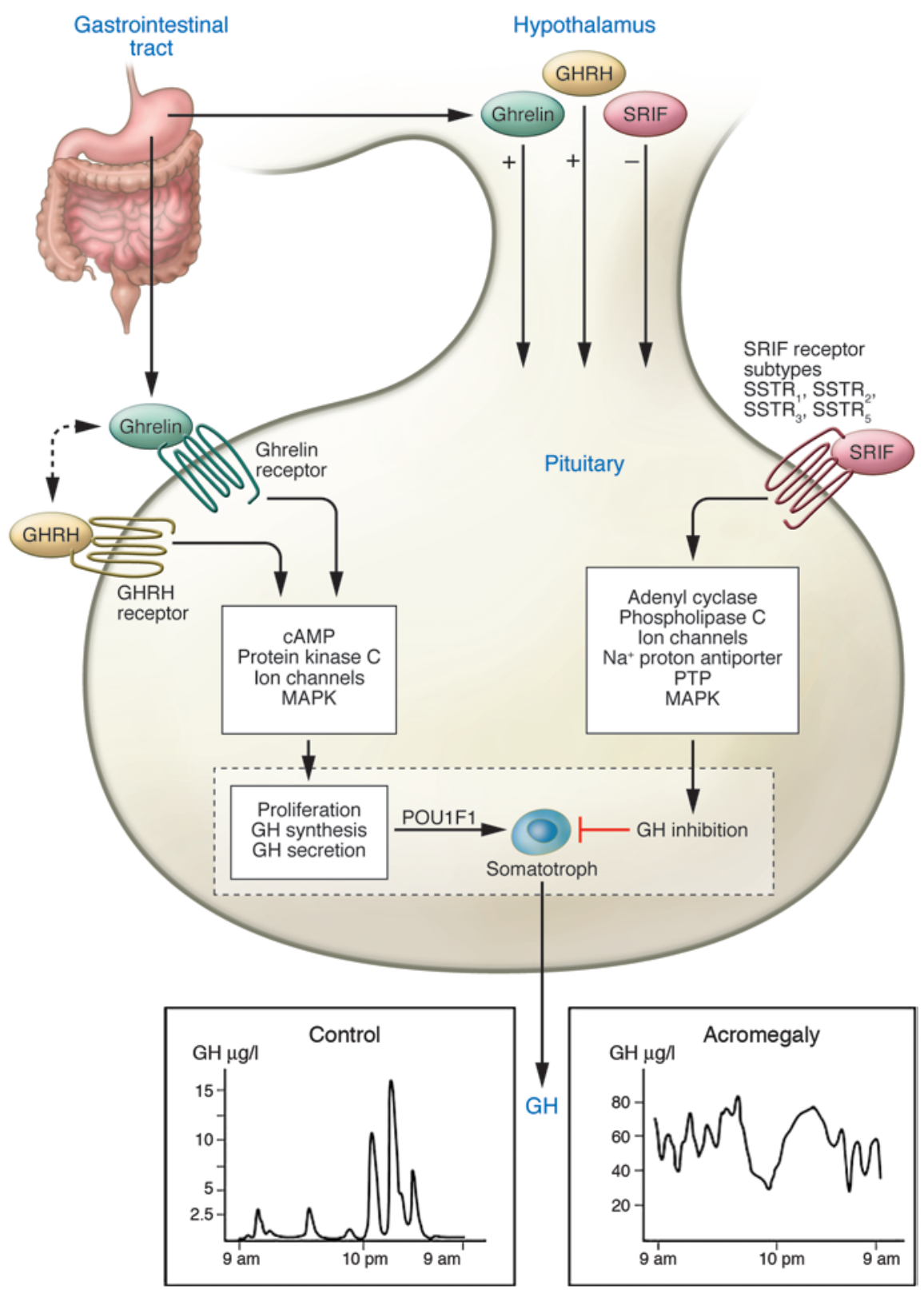

\section{Figure 2}

Normal and disrupted GHRH-GH-IGF1 axis and molecular targets for therapy. Pituitary somatotroph cell development and gene expression are determined by the POU1F1 transcription factor. Net $\mathrm{GH}$ secretion is determined by integration of hypothalamic, nutritional, hormonal, and intrapituitary signals. $\mathrm{GH}$ synthesis and secretion are induced by hypothalamic GHRH and gut-derived ghrelin. GHRH may also act as a coagonist for the ghrelin receptor (28). Hypothalamic SRIF suppresses GH secretion mainly by highaffinity binding to SSTR 2 and SSTR Seceptor $_{5}$ subtypes expressed on somatotrophs (90). SSTR ligands (SRLs) signal through SSTR 2 and $\mathrm{SSTR}_{5}$ to control GH hypersecretion and shrink tumor mass. GH secretion patterns in a normal subject and in acromegaly are depicted in the insets showing secretory bursts (mainly at night) and daytime troughs. Insets modified with permission from Expert opinion on biological therapy (S41). evoke pleiotropic cell responses including IGF1 synthesis, glucose metabolism, cell proliferation, and cytoskeletal changes.

STAT5b is the key intracellular molecule required for $\mathrm{GH}$ mediation of postnatal growth, adipose tissue function, and sexual dimorphism of hepatic gene expression (24). Importantly, GH-activated STAT5b induces IGF1 gene transcription (S9), and several lines of evidence point to this pathway as being critical for initiating and maintaining skeletal growth. Male Stat $5 b^{-/-}$mice exhibit impaired growth, attenuated circulating IGF1 levels, and insensitivity to injected GH (S10). Hepatic IGF1 is induced by constitutively active STAT5b, while a dominant negative STAT5b construct prevents $\mathrm{GH}$-induced IGF1 expression (S11). In humans, STAT mutations result in relative $\mathrm{GH}$ insensitivity and growth retardation (32). GH also induces early response genes that precede cell growth and differentiation signals (33) mediated by CCAAT enhancer-binding protein $\beta$ and serum response element sites on the $c$-fos promoter.
The GHR may also translocate to the nucleus by the importin $\alpha / \beta$ pathway in conjunction with coactivator activator (CoAA). Gene targets for nuclear-mediated GHR action are predominantly proproliferative. Forced GHR targeting to the cell nucleus also enhances cell proliferation and transformation responsiveness to autocrine-derived GH. Thus, CoAA and activated STAT5 are both required for $\mathrm{GH}$-dependent proproliferative actions of nuclear GHR (34).

STAT5b mediates sexually dimorphic GH signals. Females exhibit more frequent GH secretory pulses and shorter interpulse nadir intervals, leading to relative desensitization of female hepatic STAT5 induction by GH as compared with that of males. Targeted disruption of STAT5b leads to male-selective reduced growth rates and loss of gender-specific hepatic gene induction (35).

GHR insensitivity may occur as a consequence of extracellular receptor domain cleavage as well as toxin-induced proteolysis, 


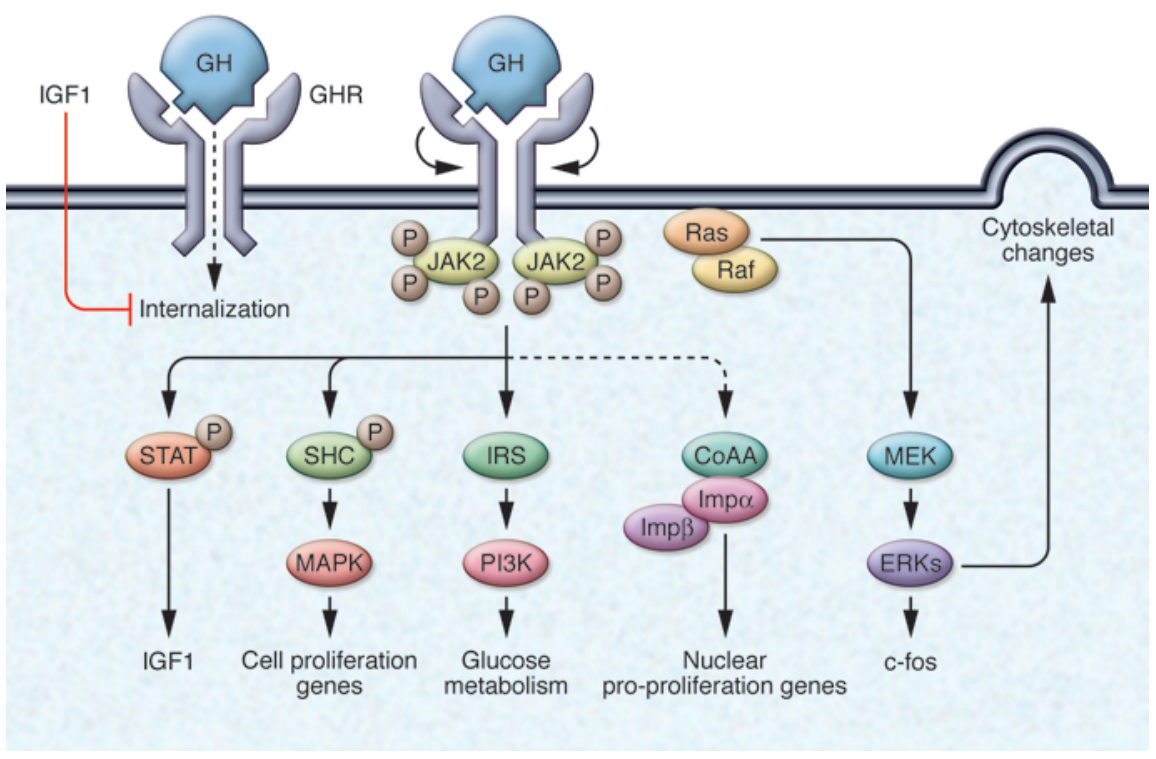

\section{Figure 3}

$\mathrm{GH}$ action. $\mathrm{GH}$ binds to the GHR dimer, which undergoes internal rotation, resulting in JAK2 phosphorylation $(\mathrm{P})$ and subsequent signal transduction. GH signaling is mediated by JAK2 phosphorylation of depicted signaling molecules or by JAK2-independent signaling including Src/ERK pathways (S42). Ligand binding to a preformed GHR dimer results in internal rotation and subsequent phosphorylation cascades. GH targets include IGF-I, c-fos, cell proliferation genes, glucose metabolism, and cystoskeletal proteins. GHR internalization and translocation (dotted lines) induce nuclear proproliferation genes via importin $\alpha / \beta$ (Imp $\alpha / \operatorname{Imp} \beta)$ coactivator (CoAA) signaling. IGF-I may also block GHR internalization, acting in a feedback loop. The GHR antagonist, pegvisomant, blocks GHR signaling; SRLs also attenuate GH binding and signaling (not shown). which abrogates signaling (S11). GHR cell-surface translocation is also directly inhibited by IGF1, likely contributing to a local feedback loop (36) (Figure 3).

\section{IGF1}

IGF1, the polypeptide target hormone for GH, is synthesized in the liver and extrahepatic tissues (principally bone, muscle, and kidney) and also in the pituitary gland itself. IGF1 mediates most of the growth-promoting actions of GH (37). Acting at both endocrine and paracrine levels, IGF1 exerts negative feedback regulation of $\mathrm{GH}$ synthesis and secretion (38). Approximately $80 \%$ of circulating IGF1 originates from the liver, and high-affinity binding proteins including IGF-binding protein 3 (IGFBP3) and acid-labile subunit (ALS) transport and also mediate IGF1 peptide activity by regulating IGF1 cell-surface receptor access (39). As IGF1 receptors are ubiquitously expressed, widespread enhanced cell proliferation as well as metabolic actions are triggered by elevated IGF1 concentrations. IGF1 acts in an endocrine fashion to mediate tissue growth, or locally synthesized IGF1 acts in an autocrine/paracrine manner to regulate local GH target tissue growth. Ultimately, organ growth responses to IGF1 are determined by the intrinsic replicative potential of local tissues. Observations that doubly mutant $\mathrm{Ghr} \mathrm{r}^{--} \mathrm{I} g \mathrm{fl}^{-/-}$mice exhibit more severe growth retardation than animals with either single-gene deletion alone indicate that anabolic actions of GH, especially on muscle, may also be distinctively direct and not necessarily IGF1 dependent (40). GH acts directly to induce germinal epiphyseal cells, while IGF1 acts to induce chondrocyte proliferation (41), and based on results derived from transgenic mice with respective deletions of GHR or IGF1 (42), both GH- and IGF1-mediated signaling appear additive in enabling growth, while IGFI may attenuate metabolic effects of $\mathrm{GH}$ (43).

\section{GH and IGF1 signaling in acromegaly}

In acromegaly, cellular responses elicited by high GH levels overwhelm intracellular mechanisms attenuating GH signaling, including those mediated by SOCS, Src kinases, and tyrosine phosphatase pathways (24).
An in-frame deletion in exon 3 results in a GHR isoform devoid of 22 aa (known as d3-GHR), which is associated with enhanced GH responsiveness, as evidenced by higher STAT5 activation and accelerated growth (44). d3-GHR is also associated with a more florid clinical and biochemical acromegaly phenotype and relative resistance of IGF1 levels to acromegaly treatment interventions (45, S12).

Although mice overexpressing transgenic GH or IGF1 exhibit enhanced somatic growth reminiscent of acromegaly, several distinctive features point to unique independent target functions for GH and IGF1 (46, S13). For example, transgenic mice overexpressing GH, but not IGF1, exhibit liver, spleen, and kidney enlargement with features of renal glomerulosclerosis. In contrast, mice overexpressing IGF1 are obese, unlike GH transgenics (S13). This phenotype recapitulates acromegaly with reduced fat mass and increased lean body mass. To what extent GH-induced hyperinsulinemia, manifest in GH transgenic mice but not in IGF1 transgenic animals, contributes to the hypersomatotrophic phenotype is unclear. The body of experimental evidence indicates that GH actions in bone and soft tissue require IGF1 to enable a maximally robust tissue response (47).

\section{Somatotroph adenoma pathogenesis}

Pituitary tumors are commonly encountered monoclonal adenomas that account for approximately $15 \%$ of all intracranial tumors. These invariably benign tumors arise from highly differentiated anterior pituitary cells expressing hormone gene products including GH, PRL, ACTH, TSH, and the gonadotropins follicle-stimulating hormone (FSH) and luteinizing hormone (LH). These tumors may secrete hormones excessively, leading to characteristic clinical features including acromegaly, Cushing disease, and hyperprolactinemia. More commonly, they are nonfunctional and lead primarily to hypogonadism and compressive pituitary failure (48).

Mechanistic studies of human pituitary tumors have been constrained due to inaccessibility of the gland for biopsy, lack of functional cell lines, and unique differentiated tumor subtype behavior. In most cases of acromegaly, GH hypersecretion is derived from somatotroph cell tumors (see Sidebar 2). Autonomous GH secretion by distinct somatotroph adenomas derived from the POU1F1 


\section{Sidebar 2}

\section{Glossary of GH-expressing lesions}

Densely granulated $\mathrm{GH}$-cell adenoma

Sparsely granulated GH-cell adenoma

Mixed GH and PRL

mammosomatotroph adenomas

Acidophilic stem cell adenomas

Plurihormonal GH-cell adenoma

Silent GH-secreting adenoma

Somatotroph hyperplasia

Ectopic GH-cell adenoma

Empty sella tumor

GH-cell carcinoma

GH-secreting extrapituitary tumor

latrogenic
Pure GH secreting; usually in older patients with minimally elevated GH levels

Pure GH secreting; usually in younger patients with high GH levels and aggressive growth

PRL and GH secretion by monomorphous mammosomatotrophs or mixed somatotrophs and lactotrophs. May occur with gigantism.

$\mathrm{PRL}$ and GH secretion by precursor cell tumor; usually aggressive and may occur in younger patients with gigantism

Secretes GH plus PRL, ACTH, or rarely, TSH

Expresses GH without hypersecretion or acromegaly

Usually caused by tumor secreting ectopic GHRH (e.g., carcinoid)

Arises in remnant nasopharyngeal pituitary tissue

Tumor remnants secreting $\mathrm{GH}$ arising in rim of pituitary tissue

Exceedingly rare with extracranial metastases

Abdominal, pancreatic, or lymphoma; very rare

$\mathrm{GH}$ administration transcription factor cell lineage characterizes a distinct balance of $\mathrm{GH}$ secretion versus somatotroph trophic activity. GH-secreting tumor formation ensues as a consequence of unrestrained somatotroph proliferation associated with intrinsic cell-cycle dysfunction as well as altered endocrine and or paracrine factors regulating $\mathrm{GH}$ synthesis, GH secretion, and somatotroph cell growth.

$\mathrm{GH}$-secreting adenomas very rarely exhibit activating ras mutations in invasive or metastatic lesions (49, S14). Uniquely, pituitary mitotic activity is relatively low, even in invasive adenomas. Several growth factors, including dysregulated receptors for fibroblast growth factors, dopamine, estrogen, and nerve growth factor (50), have been implicated predominantly in prolactinoma pathogenesis, but not uniformly in acromegaly (Table 1).

\section{cAMP signaling}

Several lines of evidence support the role of the GHRH-cAMP signaling pathway in mediating somatotroph tumorigenesis (Figure 4). Ectopic GHRH production by peripheral carcinoid tumors (51) leads to somatotroph hyperplasia and GH hypersecretion, but rarely adenoma formation. GHRH signals via the GHRH receptor (GHRH-R), a G protein-coupled receptor, by inducing cAMP, which induces GH transcription mediated by cAMP response element-binding protein (CREB). A constitutively activated murine pituitary-directed $G$ protein subunit $(\mathrm{Gs})$ transgene resulted in high GH levels and gigantism (S15). Guanine nucleotide-binding protein, $\alpha$ stimulating (GNAS) encodes the stimulatory Gs (Gs $\alpha)$, and activating GNAS mutations lead to constitutively elevated cAMP levels, protein kinase A activity, and GH synthesis and secretion (52). Postzygotic GNAS mutations result in a mosaic pattern of organ specificity with clinical features of McCune-Albright syndrome (OMIM 174800), including pigmented skin lesions and polyostotic fibrous dysplasia, and endocrine dysfunction including precocious puberty, thyrotoxicosis, and GH and ACTH hypersecretion (53). GH hypersecretion likely occurs as a consequence of pituitary hyperplasia, and true pituitary adenomas have rarely been identified (53). About $40 \%$ of patients with sporadic acromegaly harbor GNAS mutations with aa substitutions at Arg201 or Gln227, leading to constitutively elevated cAMP (52) with no distinctive clinical phenotype. The gene is imprinted in pituitary tissue, and mutations occur in the expressed maternal allele (S16). CREB is con- stitutively activated in GH-secreting adenomas independently of the GNAS mutation (54) and likely a final common pathway for cAMP signaling for a subset of adenomas.

Inactivating mutations of the protein kinase cAMP-dependent, regulatory type $1, \alpha$ (PRKAR1A) (55) gene, which encodes the type $1 \mathrm{~A}$ regulatory subunit of $\mathrm{PKA}$, lead to a rare syndrome of spotty skin pigmentation, mucosal and cardiac myxomas (benign neoplasms), and acromegaly (OMIM 160908). Although most identified patients exhibit elevated GH, IGF1, and often PRL levels, clinical manifestations of acromegaly are usually subtle. Mechanisms underlying acromegaly in these patients likely involve enhanced PKA activity in pituitary somatotroph cells. Analogous to the clinical phenotype, pituitary-specific transgenic deletion of Prkarla resulted in formation of murine tumors derived from the POU1F1 lineage (S17).

\section{Cell-cycle disruption}

Cyclin D1-dependent kinase 4 (CDK4) is required for postnatal somatotroph and lactotroph proliferation, and Cdk4-null mice are resistant to the trophic effects of GHRH (56). In contrast, retinoblastoma gene $(R b)$ inactivation leads to endocrine tumorigenesis, and $R b^{+/-}$mice develop spontaneous pituitary tumors with almost $100 \%$ penetrance $(57)$. Rb acts as a $\mathrm{G}_{1} / \mathrm{S}$ cell-cycle checkpoint control: cyclin-dependent kinases (CDKs) phosphorylate $\mathrm{Rb}$, triggering the release of members of the E2F family of transcription factors, enabling the progression of $\mathrm{S}$ phase and cell proliferation. Loss of E2F1 reduces the frequency of pituitary tumors in the $\mathrm{Rb}^{+/-} \mathrm{E} 2 \mathrm{f11^{-/- }}$ mouse, further indicating that site-selective tumorigenesis in $R b^{+/-}$ mice results from dysregulated E2F transcriptional activity (57).

MEN1. The multiple endocrine neoplasia type I (MEN1) syndrome (OMIM 131100) is an autosomal dominant disorder associated with germ-line mutations in MEN1, a tumor suppressor gene located on chromosome 11q13. The syndrome comprises a predisposition to parathyroid hyperplasia, pancreatic endocrine tumors, and pituitary adenomas. Up to $40 \%$ of affected individuals harbor pituitary tumors, and these comprise prolactinomas (60\%), GH-secreting adenomas (20\%), ACTH-secreting adenomas $(<10 \%)$, and nonfunctional adenomas $(<10 \%)(58, \mathrm{~S} 18)$. The MEN1 nuclear protein controls genome stability by repression of telomerase activity via telomerase reverse transcriptase (S19). Mechanisms for pituitary tumor pathogenesis in patients with MEN1 syndrome and disrupted MEN1, apparent from animal 


\section{Table 1}

Genes that contribute to the molecular pathogenesis of $\mathrm{GH}$-secreting adenomas

\begin{tabular}{|c|c|c|c|c|c|}
\hline Gene & Function & $\begin{array}{l}\text { Mode of activation/ } \\
\text { inactivation }\end{array}$ & $\begin{array}{l}\text { Clinical } \\
\text { context }\end{array}$ & $\begin{array}{l}\text { Specificity for GH-secreting } \\
\text { pituitary adenoma }\end{array}$ & Ref. \\
\hline GNAS & Oncogene & $\begin{array}{l}\text { Activating, } \\
\text { imprinting }\end{array}$ & $\begin{array}{c}\text { Nonfamilial, syndromic } \\
\text { or sporadic }\end{array}$ & Relatively specific & 52 \\
\hline CREB & Transcription factor & $\begin{array}{c}\text { Constitutive } \\
\text { phosphorylation }\end{array}$ & Sporadic & Relatively specific & 54 \\
\hline AIP & Tumor suppressor & Inactivating & Familial, syndromic & Relatively specific & S46 \\
\hline MEN1 & Tumor suppressor & Inactivating & Familial, syndromic & Not specific & S18 \\
\hline PRKAR1A & Tumor suppressor & Inactivating & Familial, syndromic & Not specific & 55 \\
\hline $\begin{array}{l}H-R A S \text { (Harvey rat sarcoma } \\
\text { virus oncogene) }\end{array}$ & Oncogene & Activating & Invasive or malignant & Not specific & S14 \\
\hline CCNB2 & Cyclin & Induced by HMGA & Sporadic & Not specific & 62 \\
\hline CCND1 (cyclin D1) & Oncogene & Overexpression & Sporadic & Not specific & 56 \\
\hline HMGA2 & Oncogene & Overexpression & Sporadic & Not specific & 61 \\
\hline FGFR4 (FGF receptor 4) & Oncogene & Alternative transcription & Sporadic & Not specific & S47 \\
\hline PTTG & Securin & Overexpression & Sporadic & Not specific & 63 \\
\hline$R b$ & Tumor suppressor & Epigenetic silencing & Sporadic & Not specific & 57 \\
\hline CDKN1B & CDK inhibitor & Nonsense mutation & Sporadic & Not specific & 60 \\
\hline GADD45G & Proliferation inhibitor & Epigenetic silencing & Sporadic & Not specific & 74 \\
\hline MEG3 & Proliferation inhibitor & Epigenetic silencing & Sporadic & Not specific & 75 \\
\hline
\end{tabular}

studies, include regulation of $\mathrm{p} 27$ and $\mathrm{p} 18$, both of which are implicated in pituitary tumor growth in transgenic mice models. Mice devoid of p27 exhibit striking features of gigantism with multiorgan hyperplasia and intermediate lobe pituitary tumors (S20). Thus, MEN1 enables suppression of pituitary and related neuroendocrine tumor formation, and disrupted MEN1 gene could facilitate development of these tumors. Mutations of MEN1, p18, or p27 have not been encountered in patients harboring sporadic pituitary adenomas.

When p18 homozygote mutant mice were crossed with heterozygous Men1 mutants, development of pituitary, parathyroid, thyroid, and pancreatic tumors was markedly accelerated (59). A germ-line mutation in p27 (also known as CDK inhibitor $1 \mathrm{~B}$ [CDKNIB]) has been reported in a family exhibiting features of a recessive MEN1-like phenotype (60). The index patient harbored a GH-secreting pituitary adenoma and a parathyroid adenoma. This mutation may thus account, at least in part, for the subset of apparent MEN1 subjects who do not exhibit MEN1 mutations.

$H M G A 2$. Several lines of evidence support the role of high-mobility group AT-hook 2 (HMGA2), a nuclear architectural protein, in murine and human pituitary tumorigenesis. Transgenic mice overexpressing HMGA2 exhibit highly prevalent pituitary tumors induced by (a) displacing histone deacetylase from the pRB complex; (b) acetylation and liberation of E2F1; and (c) driving pituitary cells into S phase (61). HMGA2 also induces pituitary tumor cyclin B2 (CCNB2) and directly induces CCNB2 promoter transcriptional activity. GH-secreting tumors coexpress high levels of CCNB2, HMGA1, and HMGA2 $(61,62)$.

PTTG. Pituitary tumor-transforming protein (PTTG), isolated from pituitary tumor cells, facilitates the spindle checkpoint by acting as a securin to inhibit separase and enable faithful sister chromatid separation $(63,64)$. Pttg mediates in vitro transformation and in vivo tumorigenesis in mice, and PTTG overexpression induces aneuploidy with dysregulated $\mathrm{G}_{2} / \mathrm{M}$ checkpoint surveillance, resulting in abnormal mitosis and chromosomal instability (65). PTTG modulates p53, participating in DNA damage/repair and apoptosis (66-68). PTTG is abundantly expressed in pituitary adenomas (69) and correlates with tumor invasiveness and recurrence; it is induced early in estrogen-induced pituitary tumorigenesis. PTTG elicits pituitary tumorigenesis in a transgenic model of pituitary-directed Pttg overexpression, resulting in focal pituitary hyperplasia and functional adenoma formation (70).

Pituitary senescence. Pituitary carcinomas are exceedingly rare, and only isolated cases of pituitary metastases derived from GH-secreting adenomas have been reported. GH-secreting adenomas thus represent an intriguing model for studying triggers of malignant transformation. Cellular senescence mediated by oncogenic pathways is associated with the activation of inhibitors of cell-cycle progression (such as p53-mediated p21), which protect the cell from proproliferative signals and act as a buffer against malignant transformation (71). Premature senescence may account for the overwhelming predominance of benign versus malignant GH-secreting pituitary tumors, as more than $70 \%$ of GH-secreting tumors overexpress PTTG, leading to aneuploidy and induction of senescence markers including p21 and senescence-associated $\beta$-galactosidase (72). In contrast, p21 is weakly expressed in normal pituitary tissue and undetectable in pituitary carcinomas. Senescent features of GH-secreting pituitary adenomas likely constrain malignant transformation of these invariably benign adenomas. Slow replicative pituitary cell-cycle progression is distinct from the rapid cell cycle of skin or digestive tract regenerative tissues (56), consistent with observations that pituitary tumors rarely exhibit malignant phenotypes. Thus, accumulated pituitary DNA damage and senescence, hallmarks of GH-secreting adenomas, likely enable a benign phenotype.

\section{Epigenetic mechanisms}

Loss of gene expression due to DNA hypermethylation of both alleles in GH-secreting adenomas exemplifies an epigenetic mechanism by which the loss of genes that inhibit cell proliferation results in pituitary cell proliferation (S21). CDKN2A encodes CDK inhibitor $2 \mathrm{~A}$ (also known as p16), which blocks 


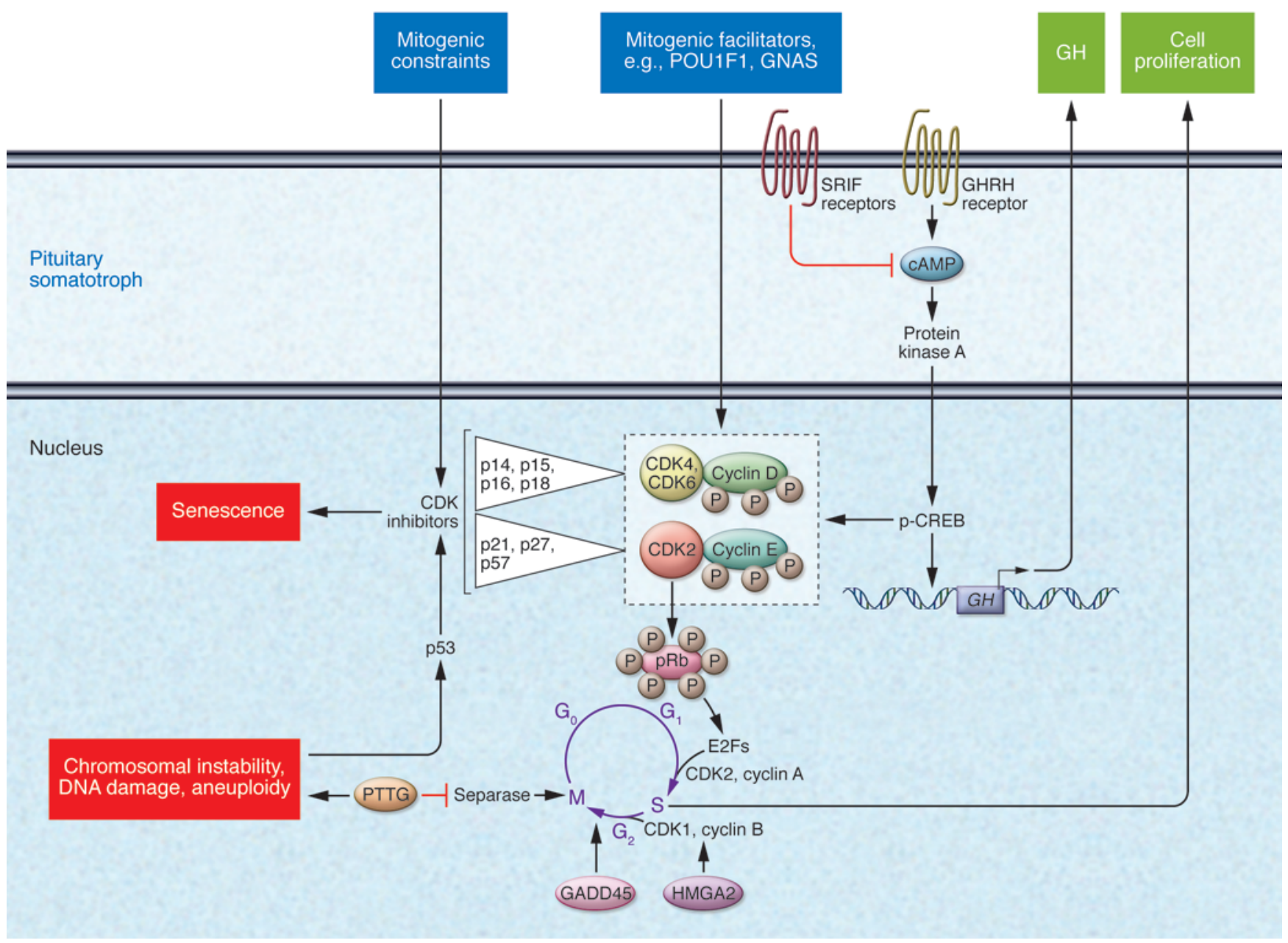

\section{Figure 4}

Depiction of intracellular pathways associated with somatotroph transformation and proliferation. GH transcription and somatotroph proliferation are induced by cAMP acting through CREB (26). SRIF inhibits cAMP and CREB activity (S43) to suppress GH secretion. Pituitary CDKs likely exhibit overlapping functions in $\mathrm{G}_{1}$ cell-cycle progression. Somatotroph mitogenic factors include POU1F1, GHRH, and GNAS as well as endocrine hormones. Mitogenic constraints include SRIF and tumor suppressor genes, including MEN1. Cell-cycle progression through G/S is mediated by CDKs that phosphorylate Rb to release E2F proteins that drive DNA synthesis. In somatotroph tumors, the cAMP pathway may be constitutively activated. Furthermore, HMGA2 and PTTG, overexpression, and CDK inhibitor loss have been shown to result in experimental pituitary tumorigenesis. Chromosomal instability, DNA damage, and senescence, hallmarks of GH-secreting adenomas, may act to constrain malignant transformation of somatotroph tumors. Modified with permission from the Journal of molecular endocrinology (ref. S44, S45; copyrighted by the Society for Endocrinology).

CDK4 from interacting with cyclin D1 and thereby preventing retinoblastoma protein $(\mathrm{Rb})$ phosphorylation. $\mathrm{Rb}$ methylation in somatotroph adenomas is variable, with inconsistent effects on tumor proliferation (73). Epigenetic silencing of p16 and p27 expression or loss of heterozygosity on chromosome 13 is also associated with $R b$ inactivation in some human pituitary tumors (73). The growth arrest and DNA damage-inducible $\gamma$ (GADD45G) and maternal expressed 3 (MEG3) genes and melanoma-associated antigen $\mathrm{A} 3$ are expressed in normal pituitary but not in pituitary adenomas (74-76).

Collectively, these observations suggest a model for pituitary adenoma growth whereby an initial proliferative phase occurs in response to growth stimuli and is then followed by irreversible growth arrest of the benign tumor. Thus, the vital hormonal functioning of the somatotroph for maintaining homeostasis control appears to be enabled by a senescent response to oncogenic stress restraining proliferation in an attempt to assure viable physiological functions.

Familial isolated pituitary adenomas. Less than 5\% of pituitary adenomas are inherited on a familial basis (77). In familial isolated pituitary adenoma (FIPA) families, prolactinomas account for about half of the adenomas, with GH-secreting and mixed GH- and PRLsecreting adenomas accounting for the remainder. Homogenous familial acromegaly (also known as isolated familial somatotropinomas [IFS]) affects younger patients usually diagnosed as teenagers or in their 20 s (78). About $25 \%$ of IFS patients present with gigantism and macroadenomas, with most not harboring a known germline mutation. Mutations in the tumor suppressor aryl hydrocarbon receptor-interacting protein (AIP) predispose to somatotroph and lactotroph tumors in $15 \%$ of patients (79) (Table 1). Two of 21 
Table 2

Acromegaly management

\begin{tabular}{|c|c|c|c|c|}
\hline & Surgery & Radiotherapy & SRL & GHR antagonist \\
\hline Mode & Transsphenoidal resection & Noninvasive & Monthly injection & Daily injection \\
\hline$-\mathrm{GH}<2.5 \mu \mathrm{g} / \mathrm{l}$ & $\begin{array}{l}\text { Macroadenomas }<50 \% \\
\text { Microadenomas }>80 \%\end{array}$ & $\sim 50 \%$ in 10 years & $\sim 65 \%$ & 0 \\
\hline - IGF1 normalized & $\begin{array}{l}\text { Macroadenomas }<50 \% \\
\text { Microadenomas }>80 \%\end{array}$ & $<30 \%$ & $\sim 65 \%$ & $>90 \%$ \\
\hline Onset & Rapid & Slow (yr) & Rapid & Rapid \\
\hline Tumor mass & Debulked or resected & Ablated & $\begin{array}{l}\text { Growth constrained or } \\
\text { tumor shrinks } \sim 50 \%\end{array}$ & Unknown \\
\hline \multicolumn{5}{|l|}{ Disadvantages } \\
\hline Hypopituitarism & $\sim 10 \%$ & $>50 \%$ & None & Low IGF1 \\
\hline Other & $\begin{array}{c}\text { Tumor persistence or recurrence, } \\
\text { diabetes insipidus, } \\
\text { local complications }\end{array}$ & $\begin{array}{l}\text { Local nerve damage, second brain } \\
\text { tumor, visual and CNS disorders, } \\
\text { cerebrovascular risk }\end{array}$ & $\begin{array}{c}\text { Gallstones, nausea, } \\
\text { diarrhea }\end{array}$ & $\begin{array}{l}\text { Elevated liver } \\
\text { enzymes }\end{array}$ \\
\hline
\end{tabular}

The goals of acromegaly management include the following: (a) control of GH and IGF1 secretion and tumor growth; (b) relief of compressive effects on CNS and vascular structures, if present; (c) preservation or restoration of pituitary hormone reserve function; and (d) treatment of comorbidities and normalization of mortality rates. Table adapted from the New England journal of medicine (1).

families with heterogenous pituitary adenoma predisposition were shown to harbor relatively large intragenic AIP deletions (S22) and a 5818-bp deletion was detected in one of 7 families affected with acromegaly. Heterozygote germ-line AIP mutations were found in 47 subjects from 9 of 26 families with familial pituitary adenomas. Of these, 31 were diagnosed with gigantism or acromegaly (80).

Given the extremely low frequency of familial pituitary tumors, the small size of affected families, and the very low prevalence of mutations within these families, costly genetic screening is not yet convincingly warranted. Accurate relatively low-cost measurement of serum IGF1 levels is currently the most effective screening for affected patients with $\mathrm{GH}$-secreting pituitary tumors.

\section{Acromegaly treatment}

Several treatment options are currently available for acromegaly (Table 2).

\section{Surgery}

Resection of GH-secreting pituitary adenomas is technically challenging because of the anatomic inaccessibility of the pituitary and bony sellar confines and the proximity of vital brain and vascular structures. Functioning tumor microfoci often invade dural spaces, are not readily visible at surgery, and continue to secrete $\mathrm{GH}$ after tumor resection. GH-secreting tumors have a propensity to invade laterally into the cavernous sinus, precluding safe resection. Tumor-associated internal carotid artery tortuosity and microaneurysms also require surgical caution and alertness. Over $90 \%$ of resections are performed via an endonasal transsphenoidal approach, often with minimally invasive endoscopic techniques. Computerized image guidance and intraoperative MRI coupled with development of microinstrumentation and optics have resulted in safe, effective, and minimally traumatic procedures when performed by skilled and experienced neurosurgeons (S23). The goal of surgery is to balance maximal tumor mass resection with preservation of normal pituitary secretory function.

About $70 \%$ of patients harboring well-circumscribed GH-secreting microadenomas less than $10 \mathrm{~mm}$ in diameter achieve longterm biochemical control after surgery (81). Unfortunately, over
$65 \%$ of $\mathrm{GH}$-secreting adenomas are invasive macroadenomas at the time of diagnosis, and surgical outcomes for these patients are far less favorable, with an approximately $50 \%$ success rate reported from most experienced clinical centers (82, S24). Markers of surgical remission include biochemical control, normal pituitary and parasellar MRI visualization, and recurrence-free postoperative duration. Determinants of surgical remission include the experience of the surgeon in resecting these challenging adenomas (83), tumor size, and degree of invasiveness (82).

Transient side effects of surgery include local hemorrhage, CSF leak, diabetes insipidus, and rarely, local infection. Permanent side effects reported in less than $5 \%$ of patients include diabetes insipidus and pituitary hormone deficiency. Clearly, the major disadvantage of surgery is persistent postoperative GH hypersecretion.

\section{Radiotherapy}

Conventional external-beam radiotherapy is administered up to a maximum of 4000-5000 cGy in 180-cGy weekly doses spread over six weeks. Overall, about $50 \%$ of patients achieve biochemical remission $(\mathrm{GH}<2 \mu \mathrm{g} / \mathrm{l}$ and normalized IGF1) after 10 years (84-86). In $77 \%$ of 884 irradiated patients, GH levels were attenuated to less than $2.5 \mu \mathrm{g} / \mathrm{l}$ by 20 years. The relatively long latency period required to achieve remission is a major disadvantage. Acquired residual pituitary damage is evident in approximately $50 \%$ of patients by 10 years. $27 \%$ exhibited TSH deficiency, $18 \%$ FSH/LH deficiency, and $15 \%$ ACTH deficiency (84). Rarely encountered local side effects include visual deficits, especially if the tumor abuts the optic chiasm, cerebral radionecrosis, cerebrovascular damage, and cognitive deficits. One percent of patients develop secondary intracranial tumors, with a latency up to 24 years (86). The reported incidence of these side effects is imprecise, due to absence of well-controlled studies and heterogeneity of radiation methodology.

\section{Stereotactic radiosurgery}

Using a ${ }^{60}$ Cobalt source, relatively narrow beams of high-dose, focused $\gamma$ radiation are delivered with stereotactic precision to a small tumor, and the approach is particularly effective in tumors less than $3 \mathrm{~cm}$ in diameter and distant from the optic tract. Five 
Table 3

Acromegaly treatments

\begin{tabular}{|c|c|c|c|c|c|c|c|}
\hline SRLS & & SSTR $_{1}$ & SSTR $_{2}$ & $\mathrm{SSTR}_{3}$ & $\mathrm{SSTR}_{4}$ & SSTR5 & D2R \\
\hline \multirow[t]{2}{*}{ Endogenous } & SRIF14 & $0.1-2.3$ & $0.2-1.3$ & $0.3-1.6$ & $0.3-1.8$ & $0.2-0.9$ & \\
\hline & SRIF28 & $0.1-2.2$ & $0.2-4.1$ & $0.3-6.1$ & $0.3-7.9$ & $0.05-0.4$ & \\
\hline \multirow[t]{2}{*}{ Clinically approved } & Octreotide & ns & 0.4 & 35 & ns & 7 & \\
\hline & Lanreotide & ns & 0.5 & 14 & ns & 4.2 & \\
\hline \multirow[t]{2}{*}{ Clinical trials } & Pasireotide & 9.3 & 1.0 & 1.5 & $>100$ & 0.2 & \\
\hline & BIM-23A760 & 622 & 0.03 & 160 & ns & 42 & 15 \\
\hline \multirow[t]{3}{*}{ Experimental } & BIM-23120 & ns & 0.3 & 412 & ns & 213 & \\
\hline & BIM-23206 & ns & 166 & ns & ns & 2.4 & \\
\hline & BIM-23244 & ns & 0.3 & 133 & ns & 0.7 & \\
\hline Octreotide & 50-400 mg s.c. every $8 \mathrm{~h}$ & & & & & & \\
\hline Octreotide LAR & 10-40 mg i.m. every 4 wk & & & & & & \\
\hline Somatuline depot (lanreotide) & $60-120 \mathrm{mg}$ deep s.c. every 4 wk & & & & & & \\
\hline \multicolumn{8}{|l|}{ GHR antagonist } \\
\hline Pegvisomant & 10-40 mg s.c. every d & & & & & & \\
\hline
\end{tabular}

Experimental ligands depicted are either SSTR 2 selective, SSTR 5 selective, or biselective for both SSTR 2 and SSTR. D2R, dopamine receptor 2; ns, nonspecific, affinity of more than $1 \mu \mathrm{mol} / \mathrm{l}$. SRL-binding affinity to transfected SSTR subtypes adapted from refs. 88,94 , and S48.

years after treatment, post-OGTT serum GH levels are less than $1 \mu \mathrm{g} / \mathrm{l}$ in approximately $50 \%$ of patients. Adenoma growth is arrested, tumor shrinkage observed in most patients, and subsequent pituitary failure occurs in approximately $25 \%$ of patients. Employing remission criteria of GH less than $2 \mu \mathrm{g} / \mathrm{l}$ and normalized IGF1, $17 \%-35 \%$ of patients remitted after 24-36 months (87). In 1567 patients undergoing radiosurgery, half of whom had prior conventional radiotherapy, 13 patients developed cerebral radionecrosis (S25). Factors determining the risk of radiation-induced pituitary failure include prior surgery, the precision of stereotactic tumor target resolution, and pituitary stalk exposure to radiation.

\section{SSTR ligands}

The two forms of endogenous SRIF, comprising 14 or 28 aa, respectively, elicit cellular responses by five ubiquitously expressed SSTR receptor subtypes (88). SSTRs act to inhibit both endocrine and exocrine hormone secretions and, less compellingly, attenuate neuroendocrine tumor cell proliferation. SSTR signaling is mainly mediated by $\mathrm{G} \alpha$ subunits to inhibit adenylyl cyclase and reduce cAMP generation. Other actions include regulating phosphotyrosine phosphatase activity, $\mathrm{K}^{+}$and $\mathrm{Ca}^{2+}$ channels, MAPK pathways, and $\mathrm{Na}^{+} / \mathrm{H}^{+}$exchange activities (S26). SSTR $2, \mathrm{SSTR}_{3}$, and SSTR exhibit constitutive signaling to pituitary cells in a ligand-free environment (89). Thus, constitutive SSTR signaling may determine ambient pituitary hormone secretion.

The availability of SSTR subtype-selective ligands has enabled elucidation of specific SST functions (88). Thus, $\mathrm{SSTR}_{2}$, and to a lesser extent $\mathrm{SSTR}_{5}$, determine secretion of GH, thyroid-stimulating hormone, and ACTH (90). GH-secreting adenomas exhibit heterogenous SSTR expression $\left(\mathrm{SSTR}_{2}>\mathrm{SSTR}_{5}>\mathrm{SSTR}_{1}>\mathrm{SSTR}_{3}\right)$, while SSTR 4 is notably undetectable in pituitary tumors $(91,92$, S27). Several lines of evidence point to a cooperative functionality of $\mathrm{SSTR}_{2}$ and $\mathrm{SSTR}_{5}$ in suppressing GH and ACTH secretion (93-95). SSTR $_{5}$ may also heterodimerize with $\mathrm{SSTR}_{2}$ to enhance availability of cell membrane receptors (96). Thus, analogs that activate both $\mathrm{SSTR}_{2}$ and $\mathrm{SSTR}_{5}$ receptors are more efficacious than respective monoselective SSTR analogs (91), and an SSTR 2 antagonist reverses the GH-suppressive effects of biselective ago- nists or their respective combinations (95). Functional agonistspecific signaling may also determine cell responses of $\mathrm{SSTR}_{2}$, $\mathrm{SSTR}_{4}$, and $\mathrm{SSTR}_{5}(\mathrm{~S} 26)$.

Clinically available somatostatin receptor ligands. Octreotide, a cyclic octapeptide, is administered by s.c. or i.v. injection. Octreotide binds avidly to $\mathrm{SSTR}_{2}$ with a $\mathrm{Kd}$ of approximately $0.4 \mathrm{pM}$, and to a lesser extent to $\mathrm{SSTR}_{5}$. The starting dose is $100-250 \mu \mathrm{g}$ every 8 hours, and up to $1.5 \mathrm{mg} / 24$ hours can be safely administered in patients with acromegaly (97, S28). Peak drug concentrations are attained within 40 minutes of injection, and the ligand exhibits a circulating half-life of up to 2 hours, as compared with approximately 2 minutes for endogenous SRIF. The long-acting release (LAR) intramuscular formulation is encapsulated within biodegradable D, L-lactic, and glycolic acid copolymer microspheres (88). The starting dose is usually $20 \mathrm{mg}$ every 28 days, with safe maximal monthly doses up to approximately $60 \mathrm{mg}$ or higher. Drug levels peak at 28 days, and plateau concentrations are sustained for approximately 14 days. When injected every 4 weeks, pharmacologically steady-state levels are achieved by the third injection. Lanreotide (BIM-23014) is incorporated into a biodegradable polymer for intramuscular injection (30 or $60 \mathrm{mg}$ ) every $7-14$ days. With an approximately five-day half-life, the molecule exhibits high $\mathrm{SSTR}_{2}$ affinity and also binds less avidly to SSTR. The long-acting lanreotide Autogel (Somatuline Depot in the USA) is available as a water-soluble, prefilled 60-, 90-, or 120-mg syringe for deep s.c. injection. Pharmacologically effective therapeutic levels of approximately $1 \mathrm{ng} / \mathrm{ml}$ are maintained for 28 days and, with a 23- to 29-day half-life, steady-state is achieved after four monthly injections. Both octreotide and lanreotide activate the SSTR 2 receptor with similar avidity, and head-to-head studies demonstrate nonsuperiority for safety and efficacy of either formulation (98).

Ubiquitous tissue distribution of SSTR receptor targets underlies the multitargeted therapeutic control elicited by somatostatin receptor ligands (SRLs) in acromegaly.

Hypothalamus. SRIF attenuates hypothalamic GHRH secretion and action by inhibiting GHRH induction of GH synthesis, secretion (99), and somatotroph cell replication (Figure 2) (S29). Ultra- 
Table 4

Treatment outcomes

\section{Observed outcomes}

Biochemical and clinical control:

Nadir GH $<1 \mu \mathrm{g} / \mathrm{l}$ after OGTT

Age-matched normal IGF1 level

Tumor stable

No comorbidities

Biochemical abnormality

Basal GH $>0.4 \mu \mathrm{g} / \mathrm{l}$

Nadir GH >1 $\mu \mathrm{g} / \mathrm{l}$ after OGTT

Elevated IGF1 level

Tumor stable

No comorbidities

Biochemically and clinically active:

Basal GH $>0.4 \mu \mathrm{g} / \mathrm{l}$

Nadir GH $>1 \mu \mathrm{g} / \mathrm{l}$

Elevated IGF1 level

Tumor growing

Active comorbidities

\section{Treatment plan}

None or no change in current treatment

Evaluate pituitary axes Annual MRI

Weigh treatment benefit vs. risks Consider new treatment if being treated

Evaluate pituitary axes $\mathrm{MRI}$ as indicated

Three outcomes each require a distinct treatment plan. Measurement of basal GH, GH after OGTT, and IGF1 levels determine degree of biochemical control. Clinical comorbidities require rigorous assessment and management to elicit optimal mortality outcomes. Based on recommendations published in ref. 8 . dian rat GH rhythm (where ultradian rhythms are recurrent periods or cycles repeated throughout a 24-hour circadian day) is mediated by tonic SRIF secretion, antagonizing GHRH action (100). SRLs also inhibit ectopic GHRH production by carcinoid tumors (S30).

Pituitary adenoma GH secretion is suppressed, leading to secondary suppression of circulating and perhaps tissue IGF1 levels. Clinical octreotide efficacy is predicted by tumor SSTR $_{2}$ expression (101, S31). Furthermore, SSTR2 gene transfer enhances octreotide responsiveness in resistant GH adenoma cells (102). In patients treated for at least six months (103-106, S32, S33) and using random fasting GH levels of less than $2.5 \mu \mathrm{g} / \mathrm{l}$ and/or normalization of age-matched IGF1 levels as efficacy markers, approximately $65 \%$ of patients treated with octreotide LAR achieved control of $\mathrm{GH}$ secretion. If a more rigorous GH cutoff of less than $1 \mu \mathrm{g} / 1$ is used, approximately $33 \%$ of patients could be defined as controlled. In 36 patients followed for 3-18 years, GH of less than $2 \mu \mathrm{g} / \mathrm{l}$ and normal IGF1 were achieved in $70 \%$ of patients (107). Drug efficacy improves with prolonged treatment duration; tachyphylaxis has not been evident, and GH and IGF1 levels continue to decline, even after 9 years of sustained treatment (105). Headache, perspiration, fatigue, ring-finger thickness, and tissue swelling improve in up to $80 \%$ of patients. Efficacy may be moderately improved by adding the dopamine receptor agonist cabergoline to enhance $\mathrm{GH}$ suppression (108). SRLs are indicated in the following instances: (a) for first-line primary therapy; (b) for individuals too frail for anesthesia; (c) for those who decline surgery; (d) preoperatively to assure maximal surgical outcomes (109); (e) postoperatively for persistent and inevitable disease; (85) or (f) while awaiting radiotherapy impact to manifest. Biochemical control by primary SRL treatment is not different from that achieved by surgery alone (110), and conversely, surgical adenoma debulking also enhances subsequent lanreotide efficacy (111).

Liver. Independently of pituitary action, SRLs act directly on the liver to regulate peripheral GH action by decreasing GHR binding and inhibiting hepatocyte IGF synthesis (112). In GH-deficient patients receiving a fixed $\mathrm{GH}$ replacement dose, octreotide also suppresses IGF1 levels, further supporting a pituitary-independent effect of the analog (113).

Pituitary adenoma growth. GH-secreting tumors, with rare exceptions, do not continue growing during SRL administration, and tumor volumes may be reduced. About $75 \%$ of patients exhibit a greater than $20 \%$ reduction in tumor volume (106). Overall, approximately $70 \%$ of patients exhibit more than $20 \%$ tumor mass shrinkage, as evidenced by MRI measurement of greatest tumor diameter or calculated cuboidal mass (114). Biochemical responsiveness does not, however, invariably predict tumor shrinkage. The cellular basis for observed reversible tumor shrinkage is unclear, and several mechanisms have been proposed: Ki67 index is lower after octreotide, suggesting decreased cell cycling in GH adenoma cells (S34), and low adenoma levels of Raf kinase inhibitory protein are associated with attenuated octreotide responsiveness (S35). SRLs also block rat adenalectomy-induced pituitary mitotic activity (S36).

Side effects. Up to $30 \%$ of patients develop asymptomatic gallstones and transient gastrointestinal disturbances. Local injection site pain and sinus bradycardia may be encountered. A metaanalysis of 31 studies showed (115) that fasting plasma insulin levels were reduced, while glycosylated hemoglobin and fasting plasma glucose levels were unchanged.

\section{New SRL molecules}

Pasireotide binds with high affinity to $\mathrm{SSTR}_{1}, \mathrm{SSTR}_{2}, \mathrm{SSTR}_{3}$, and $\mathrm{SSTR}_{5}(116)$. The molecule is currently being evaluated for treatment of octreotide-resistant GH-secreting adenomas (117). In addition to superior affinity for $\mathrm{SSTR}_{5}$ as compared with octreotide, pasireotide also acts to form unstable $\mathrm{SSTR}_{2}$ complexes with $\beta$ arrestin, resulting in rapid receptor recycling (S37).

Clinical trials are ongoing using chimeric molecules activating both $\mathrm{SSTR}_{2}$ and $\mathrm{D}_{2}$ receptors and potently suppressing both $\mathrm{GH}$ and PRL. These hybrid molecules show comparable or superior GH suppression in hGH-secreting adenoma cells compared with cotreatment with monoselective $\mathrm{D}_{2}$ and $\mathrm{SSTR}_{2}$ analogs (118). Interestingly, $\mathrm{a}_{2}$ antagonist also blocks $\mathrm{GH}$ suppression by the hybrid molecule, suggesting functional interaction between adenoma SSTR 2 and the $\mathrm{D}_{2} \mathrm{R}$ ligand. Although $\mathrm{D}_{2} \mathrm{R}$ and SSTR $\mathrm{R}_{5}$ heterooligomerize in stably transfected CHO-K1 cells (119), ligand-induced SSTR and $\mathrm{D}_{2} \mathrm{R}$ heterodimerization has not been shown in pituitary cells.

\section{GHR antagonist}

Pegvisomant is a 199-aa recombinant competitive GH antagonist mutated at Gly120Arg (Table 3). The drug abrogates GHR signaling and is pegylated to generate a stable molecule. PEG-hGHG120K binds site 1 of the GHR and abrogates site 2 binding, preventing internal receptor conformational changes required for signaling. Eight additional mutations at site 1 enhance binding of the molecule to recombinant GH-binding protein (GHBP) (120). Covalent pegylation delays renal clearance, prolonging the half-life to approximately 100 hours (121). The drug thus blocks IGF1 generation by specifically antagonizing peripheral GH action (122). 
Using conventional assays, GH levels appear to increase after drug administration, likely due to attenuation of negative IGF1 feedback on somatotroph secretion.

Efficacy. In 177 patients receiving daily pegvisomant doses of 10-30 mg, 76\% achieved normal IGF1 levels after 24 months (123), with improvement of symptoms, including soft-tissue swelling, perspiration, cardiomyopathy, and heart failure (S38). In $75 \%$ of patients resistant to maximal SRL doses, pegvisomant normalized IGF1 levels and improved cardiovascular risk markers and insulin sensitivity. Pegvisomant is additive with SRIF analogs in controlling IGF1 levels in patients resistant to SRIF alone. In 26 patients receiving monthly SRLs, addition of weekly pegvisomant injections normalized IGF1 levels in 95\% of patients (S39). Thus, longer dosing intervals and combination therapy offer effective pharmacologic control for an overwhelming majority of patients.

Side effects. About $5 \%$ of patients receiving pegvisomant develop up to 3-fold or more increased hepatic transaminase levels (123), and this is invariably reversible. Other side effects include injection-site reactions and lipohypertrophy, likely reflecting local adipocyte GH insensitivity. As loss of IGF1 negative feedback on the somatotroph could conceivably lead to persistent cell proliferation, possible continued pituitary tumor growth should be monitored by MRI, especially in those patients in whom SRLs have been discontinued. Although GH antibodies may form, pegvisomant tachyphylaxis is not observed. Pegvisomant-mediated lowering of IGF1 levels to below normal limits may result in features of adult GH deficiency.

Novel GHR antagonists in development include small orally active molecules, recombinant $\mathrm{GH}$ antagonists, GHR antibodies, and antisense molecules directed against the GHR.

\section{Assessment of treatment outcomes}

Accurate biochemical assessment of surgical, medical, and radiotherapy treatment outcomes has been challenging due to inconsistency of reported assays (124) and lack of uniformity in defining treatment goals (8). Although tight medical control of GH improves clinical outcomes, a significant number of patients exhibit persistent GH hypersecretion. Cardiac failure and sleep apnea may partially resolve with disease control; however, intractable failure, arrhythmias, valvular dysfunction, and hypertension rarely resolve in patients achieving biochemical control, and aggressive ongoing treatment is required. Enhanced outcomes are achieved by increasing SRL doses, maximizing dose timing, and using combination treatments (Table 4).

Remarkable recent progress in understanding mechanisms underlying acromegaly pathogenesis has spawned novel peptide therapies to control the disease. New therapeutic molecules currently in trials will hopefully offer further safe benefit to those patients resistant to current therapeutic modes for this inexorably progressive disorder.

\section{Acknowledgments}

Work in the author's laboratory was supported by NIH grant CA 075979, the Doris Factor Molecular Endocrinology Laboratory, and the Helene and Phillip Hixon Chair in Investigative Medicine. The author thanks Grace G. Labrado for expert secretarial assistance.

Address correspondence to: Shlomo Melmed, Cedars-Sinai Medical Center, 8700 Beverly Blvd., Room 2015, Los Angeles, California 90048, USA. Phone: (310) 423-4691; Fax: (310) 423-0119; E-mail: Melmed@csmc.edu.
1. Melmed, S. 2006. Medical progress: acromegaly. N. Engl. J. Med. 355:2558-2573.

2. Ayuk, J., and Sheppard, M.C. 2008. Does acromegaly enhance mortality? Rev. Endocr. Metab. Disord. 9:33-39.

3. Nachtigall, L., et al. 2008. Changing patterns in diagnosis and therapy of acromegaly over two decades. J. Clin. Endocrinol. Metab. 93:2035-2041.

4. Molitch, M.E. 1992. Clinical manifestations of acromegaly. Endocrinol. Metab. Clin. North Am. 21:597-614.

5. Colao, A., Ferone, D., Marzullo, P., and Lombardi, G. 2004. Systemic complications of acromegaly: epidemiology, pathogenesis, and management. Endocr. Rev. 25:102-152.

6. Sata, A., and Ho, K.K. 2007. Growth hormone measurements in the diagnosis and monitoring of acromegaly. Pituitary. 10:165-172.

7. Pokrajac, A., et al. 2007. Variation in GH and IGF-I assays limits the applicability of international consensus criteria to local practice. Clin. Endocrinol. (Oxf). 67:65-70.

8. Melmed, S., et al. 2009. Guidelines for acromegaly management: an update. J. Clin. Endocrinol. Metab. 94:1509-1517.

9. Freda, P.U., Post, K.D., Powell, J.S., and Wardlaw, S.L. 1998. Evaluation of disease status with sensitive measures of growth hormone secretion in 60 postoperative patients with acromegaly. J. Clin. Endocrinol. Metab. 83:3808-3816.

10. Clemmons, D.R., et al. 1979. Evaluation of acromegaly by radioimmunoassay of somatomedin-C. N. Engl. J. Med. 301:1138-1142.

11. Brabant, G., et al. 2003. Serum insulin-like growth factor I reference values for an automated chemiluminescence immunoassay system: results from a multicenter study. Horm. Res. 60:53-60.

12. Massart, C., and Poirier, J.Y. 2006. Serum insulin- like growth factor-I measurement in the follow-up of treated acromegaly: comparison of four immunoassays. Clin. Chim. Acta. 373:176-179.

13. Nguyen, T.V., et al. 2008. Within-subject variability and analytic imprecision of insulinlike growth factor axis and collagen markers: implications for clinical diagnosis and doping tests. Clin. Chem. 54:1268-1276.

14. Holdaway, I.M., Bolland, M.J., and Gamble, G.D. 2008. A meta-analysis of the effect of lowering serum levels of GH and IGF-I on mortality in acromegaly. Eur. J. Endocrinol. 159:89-95.

15. Dekkers, O.M., Biermasz, N.R., Pereira, A.M., Romijn, J.A., and Vandenbroucke, J.P. 2008. Mortality in acromegaly: a metaanalysis. J. Clin. Endocrinol. Metab. 93:61-67.

16. Ayuk, J., et al. 2004. Growth hormone and pituitary radiotherapy, but not serum insulin-like growth factor-I concentrations, predict excess mortality in patients with acromegaly. J. Clin. Endocrinol. Metab. 89:1613-1617.

17. Colao, A., et al. 1999. Impact of patient's age and disease duration on cardiac performance in acromegaly: a radionuclide angiography study. J. Clin. Endocrinol. Metab. 84:1518-1523.

18. Chanson, P., et al. 1990. Cardiovascular effects of the somatostatin analog octreotide in acromegaly. Ann. Intern. Med. 113:921-925.

19. Kamenicky, P., et al. 2008. Epithelial sodium channel is a key mediator of growth hormone-induced sodium retention in acromegaly. Endocrinology. 149:3294-3305.

20. Zhu, X., Lin, C.R., Prefontaine, G.G., Tollkuhn, J., and Rosenfeld, M.G. 2005. Genetic control of pituitary development and hypopituitarism. Curr. Opin. Genet. Dev. 15:332-340.

21. Pulichino, A.-M., Vallette-Kasic, S., and Drouin, J. 2004. Transcriptional regulation of pituitary gland development: binary choices for cell differentiation. Curr. Opin. Endocrinol. Diabetes Obes. 11:13-17.

22. Miller, W.L., and Eberhardt, N.L. 1983. Structure and evolution of the growth hormone gene family. Endocr. Rev. 4:97-130.

23. Chen, X.Z., et al. 1992. Conversion of bovine growth hormone cysteine residues to serine affects secretion by cultured cells and growth rates in transgenic mice. Mol. Endocrinol. 6:598-606.

24. Lanning, N.J., and Carter-Su, C. 2006. Recent advances in growth hormone signaling. Rev. Endocr. Metab. Disord. 7:225-235.

25. Tannenbaum, G.S., Epelbaum, J., and Bowers, C.Y. 2003. Interrelationship between the novel peptide ghrelin and somatostatin/growth hormone-releasing hormone in regulation of pulsatile growth hormone secretion. Endocrinology. 144:967-974.

26. Mayo, K.E., et al. 2000. Regulation of the pituitary somatotroph cell by GHRH and its receptor. Recent Prog. Horm. Res. 55:237-266; discussion 266-237.

27. Kojima, M., et al. 1999. Ghrelin is a growth-hormone-releasing acylated peptide from stomach. Nature. 402:656-660.

28. Casanueva, F.F., et al. 2008. Growth hormonereleasing hormone as an agonist of the ghrelin receptor GHS-R1a. Proc. Natl. Acad. Sci. U. S. A. 105:20452-20457.

29. Ho, K.Y., et al. 1988. Fasting enhances growth hormone secretion and amplifies the complex rhythms of growth hormone secretion in man. J. Clin. Invest. 81:968-975.

30. Brooks, A.J., Wooh, J.W., Tunny, K.A., and Waters, M.J. 2008. Growth hormone receptor; mechanism of action. Int. J. Biochem. Cell Biol. 40:1984-1989.

31. Brown, R.J., et al. 2005. Model for growth hormone receptor activation based on subunit rotation within a receptor dimer. Nat. Struct. Mol. Biol. 12:814-821. 
32. Kofoed, E.M., et al. 2003. Growth hormone insensitivity associated with a STAT5b mutation. $N$. Engl. J. Med. 349:1139-1147.

33. Gurland, G., Ashcom, G., Cochran, B.H., and Schwartz, J. 1990. Rapid events in growth hormone action. Induction of c-fos and c-jun transcription in 3T3-F442A preadipocytes. Endocrinology. 127:3187-3195.

34. Conway-Campbell, B.L., Brooks, A.J., Robinson, P.J., Perani, M., and Waters, M.J. 2008. The extracellular domain of the growth hormone receptor interacts with coactivator activator to promote cell proliferation. Mol. Endocrinol. 22:2190-2202.

35. Udy, G.B., et al. 1997. Requirement of STAT5b for sexual dimorphism of body growth rates and liver gene expression. Proc. Natl. Acad. Sci. U. S. A. 94:7239-7244.

36. Leung, K.C., Waters, M.J., Markus, I., Baumbach, W.R., and Ho, K.K. 1997. Insulin and insulin-like growth factor-I acutely inhibit surface translocation of growth hormone receptors in osteoblasts: a novel mechanism of growth hormone receptor regulation. Proc. Natl. Acad. Sci. U. S. A. 94:11381-11386.

37. Clemmons, D. 2006. Insulin-like growth factor 1 and its binding proteins. In Endocrinology. L.J. DeGroot and J.L. Jameson, editors. Elsevier Saunders. Philadelphia, Pennsylvania, USA. 643-673.

38. Melmed, S., et al. 1996. IGF-I receptor signalling: lessons from the somatotroph. Recent Prog. Horm. Res. 51:189-215; discussion 215-186.

39. Clemmons, D.R. 2001. Use of mutagenesis to probe IGF-binding protein structure/function relationships. Endocr. Rev. 22:800-817.

40. LeRoith, D., and Yakar, S. 2007. Mechanisms of disease: metabolic effects of growth hormone and insulin-like growth factor 1. Nat. Clin. Pract. Endocrinol. Metab. 3:302-310.

41. Ohlsson, C., Nilsson, A., Isaksson, O., and Lindahl, A. 1992. Growth hormone induces multiplication of the slowlycycling germinal cells of the rat tibial growth plate. Proc. Natl. Acad. Sci. U. S. A. 89:9826-9830.

42. Lupu, F., Terwilliger, J.D., Lee, K., Segre, G.V., and Efstratiadis, A. 2001. Roles of growth hormone and insulin-like growth factor 1 in mouse postnatal growth. Dev. Biol. 229:141-162.

43. Fan, Y., et al. 2009. Liver-specific deletion of the growth hormone receptor reveals essential role of growth hormone signaling in hepatic lipid metabolism. J. Biol. Chem. 284:19937-19944.

44. Dos Santos, C., et al. 2004. A common polymorphism of the growth hormone receptor is associated with increased responsiveness to growth hormone. Nat. Genet. 36:720-724.

45. Mercado, M., et al. 2008. Clinical and biochemical impact of the $\mathrm{d} 3$ growth hormone receptor genotype in acromegaly. J. Clin. Endocrinol. Metab. 93:3411-3415.

46. Behringer, R.R., et al. 1990. Expression of insulin-like growth factor I stimulates normal somatic growth in growth hormone-deficient transgenic mice. Endocrinology. 127:1033-1040.

47. Kim, H., et al. 2005. Intact insulin and insulin-like growth factor-I receptor signaling is required for growth hormone effects on skeletal muscle growth and function in vivo. Endocrinology. 146:1772-1779.

48. Melmed, S. 2003. Mechanisms for pituitary tumorigenesis: the plastic pituitary. J. Clin. Invest. 112:1603-1618.

49. Karga, H.J., Alexander, J.M., Hedley-Whyte, E.T., Klibanski, A., and Jameson, J.L. 1992. Ras mutations in human pituitary tumors. J. Clin. Endocrinol. Metab. 74:914-919.

50. Asa, S.L., and Ezzat, S. 2009. The pathogenesis of pituitary tumors. Annu. Rev. Pathol. 4:97-126.

51. Thorner, M.O., et al. 1982. Somatotroph hyperplasia. Successful treatment of acromegaly by removal of a pancreatic islet tumor secreting a growth hormone-releasing factor. J. Clin. Invest. 70:965-977.
52. Vallar, L., Spada, A., and Giannattasio, G. 1987. Altered Gs and adenylate cyclase activity in human GH-secreting pituitary adenomas. Nature. 330:566-568

53. Weinstein, L.S., et al. 1991. Activating mutations of the stimulatory $G$ protein in the McCune-Albright syndrome. N. Engl.J. Med. 325:1688-1695.

54. Bertherat, J., Chanson, P., and Montminy, M. 1995. The cyclic adenosine 3',5'-monophosphateresponsive factor CREB is constitutively activated in human somatotroph adenomas. Mol. Endocrinol. 9:777-783.

55. Boikos, S.A., and Stratakis, C.A. 2007. Carney complex: the first 20 years. Curr. Opin. Oncol. 19:24-29.

56. Jirawatnotai, S., et al. 2004. Cdk4 is indispensable for postnatal proliferation of the anterior pituitary. J. Biol. Chem. 279:51100-51106.

57. Yamasaki, L., et al. 1998. Loss of E2F-1 reduces tumorigenesis and extends the lifespan of $\mathrm{Rb} 1(+/-)$ mice. Nat. Genet. 18:360-364.

58. Marx, S.J., et al. 1999. Multiple endocrine neoplasia type 1: clinical and genetic features of the hereditary endocrine neoplasias. Recent Prog. Horm. Res. 54:397-438; discussion 438-399.

59. Bai, F., Pei, X.H., Nishikawa, T., Smith, M.D., and Xiong, Y. 2007. p18Ink4c, but not p27Kip1, collaborates with Men 1 to suppress neuroendocrine organ tumors. Mol. Cell Biol. 27:1495-1504.

60. Pellegata, N.S., et al. 2006. Germ-line mutations in $\mathrm{p} 27 \mathrm{Kip} 1$ cause a multiple endocrine neoplasia syndrome in rats and humans. Proc. Natl. Acad. Sci. U. S. A. 103:15558-15563.

61. De Martino, I., et al. 2009. HMGA proteins up-regulate CCNB2 gene in mouse and human pituitary adenomas. Cancer Res. 69:1844.

62. Fedele, M., et al. 2006. HMGA2 induces pituitary tumorigenesis by enhancing E2F1 activity. Cancer Cell. 9:459-471.

63. Pei, L., and Melmed, S. 1997. Isolation and characterization of a pituitary tumor-transforming gene (PTTG). Mol. Endocrinol. 11:433-441.

64. Zou, H., McGarry, T.J., Bernal, T., and Kirschner, M.W. 1999. Identification of a vertebrate sister-chromatid separation inhibitor involved in transformation and tumorigenesis. Science. 285:418-422.

65. Vlotides, G., Eigler, T., and Melmed, S. 2007. Pituitary tumor-transforming gene: physiology and implications for tumorigenesis. Endocr. Rev. 28:165-186.

66. Bernal, J.A., et al. 2002. Human securin interacts with p53 and modulates p53-mediated transcriptional activity and apoptosis. Nat. Genet. 32:306-311.

67. Bernal, J.A., et al. 2008. Proliferative potential after DNA damage and non-homologous end joining are affected by loss of securin. Cell Death Differ. 15:202-212.

68. Kim, D.S., et al. 2007. Securin induces genetic instability in colorectal cancer by inhibiting double-stranded DNA repair activity. Carcinogenesis. 28:749-759.

69. Heaney, A.P., Horwitz, G.A., Wang, Z., Singson, R., and Melmed, S. 1999. Early involvement of estrogen-induced pituitary tumor transforming gene and fibroblast growth factor expression in prolactinoma pathogenesis. Nat. Med. 5:1317-1321.

70. Abbud, R.A., et al. 2005. Early multipotential pituitary focal hyperplasia in the alpha-subunit of glycoprotein hormone-driven pituitary tumortransforming gene transgenic mice. Mol. Endocrinol. 19:1383-1391.

71. Kuilman, T., et al. 2008. Oncogene-induced senescence relayed by an interleukin-dependent inflammatory network. Cell. 133:1019-1031.

72. Chesnokova, V., et al. 2008. p21(Cip1) restrains pituitary tumor growth. Proc. Natl. Acad. Sci. U. S. A. 105:17498-17503.

73. Farrell, W.E. 2006. Pituitary tumours: findings from whole genome analyses. Endocr. Relat. Cancer.
13:707-716.

74. Zhang, X., et al. 2002. Loss of expression of GADD45 gamma, a growth inhibitory gene, in human pituitary adenomas: implications for tumorigenesis. J. Clin. Endocrinol. Metab. 87:1262-1267.

75. Gejman, R., et al. 2008. Selective loss of MEG3 expression and intergenic differentially methylated region hypermethylation in the MEG3/DLK1 locus in human clinically nonfunctioning pituitary adenomas. J. Clin. Endocrinol. Metab. 93:4119-4125.

76. Zhu, X., Asa, S.L., and Ezzat, S. 2008. Fibroblast growth factor 2 and estrogen control the balance of histone 3 modifications targeting MAGE-A3 in pituitary neoplasia. Clin. Cancer Res. 14:1984-1996.

77. Beckers, A., and Daly, A.F. 2007. The clinical, pathological, and genetic features of familial isolated pituitary adenomas. Eur. J. Endocrinol. 157:371-382.

78. Gadelha, M.R., et al. 2000. Isolated familial somatotropinomas: establishment of linkage to chromosome 11q13.1-11q13.3 and evidence for a potential second locus at chromosome 2p16-12. J. Clin. Endocrinol. Metab. 85:707-714.

79. Georgitsi, M., et al. 2007. Molecular diagnosis of pituitary adenoma predisposition caused by aryl hydrocarbon receptor-interacting protein gene mutations. Proc. Natl. Acad. Sci. U. S. A. 104:4101-4105.

80. Leontiou, C.A., et al. 2008. The role of the aryl hydrocarbon receptor-interacting protein gene in familial and sporadic pituitary adenomas. J. Clin. Endocrinol. Metab. 93:2390-2401.

81. Kreutzer, J., Vance, M.L., Lopes, M.B., and Laws, E.R., Jr. 2001. Surgical management of GH-secreting pituitary adenomas: an outcome study using modern remission criteria. J. Clin. Endocrinol. Metab. 86:4072-4077.

82. Shimon, I., Cohen, Z.R., Ram, Z., and Hadani, M. 2001. Transsphenoidal surgery for acromegaly: endocrinological follow-up of 98 patients. Neurosurgery. 48:1239-1243; discussion 1244-1235.

83. Ahmed, S., et al. 1999. Outcome of transphenoidal surgery for acromegaly and its relationship to surgical experience. Clin. Endocrinol. (Oxf). 50:561-567.

84. Jenkins, P.J., Bates, P., Carson, M.N., Stewart, P.M., and Wass, J.A. 2006. Conventional pituitary irradiation is effective in lowering serum growth hormone and insulin-like growth factor-I in patients with acromegaly. J. Clin. Endocrinol. Metab. 91:1239-1245.

85. Jallad, R.S., Musolino, N.R., Kodaira, S., Cescato, V.A., and Bronstein, M.D. 2007. Does partial surgical tumour removal influence the response to octreotide-LAR in acromegalic patients previously resistant to the somatostatin analogue? Clin. Endocrinol. (Oxf). 67:310-315.

86. Minniti, G., Traish, D., Ashley, S., Gonsalves, A., and Brada, M. 2005. Risk of second brain tumor after conservative surgery and radiotherapy for pituitary adenoma: update after an additional 10 years. J. Clin. Endocrinol. Metab. 90:800-804.

87. Castinetti, F., et al. 2005. Outcome of gamma knife radiosurgery in 82 patients with acromegaly: correlation with initial hypersecretion. J. Clin. Endocrinol. Metab. 90:4483-4488.

88. Weckbecker, G., et al. 2003. Opportunities in somatostatin research: biological, chemical and therapeutic aspects. Nat. Rev. Drug Discov. 2:999-1017.

89. Ben-Shlomo, A., et al. 2009. Constitutive somatostatin receptor activity determines tonic pituitary cell response. Mol. Endocrinol. 23:337-348.

90. Shimon, I., et al. 1997. Somatostatin receptor subtype specificity in human fetal pituitary cultures. Differential role of SSTR2 and SSTR5 for growth hormone, thyroid-stimulating hormone, and prolactin regulation. J. Clin. Invest. 99:789-798.

91. Shimon, I., et al. 1997. Somatostatin receptor (SSTR) subtype-selective analogues differentially suppress in vitro growth hormone and prolactin in human pituitary adenomas. Novel potential therapy for functional pituitary tumors. J. Clin. Invest. 
100:2386-2392.

92. Greenman, Y., and Melmed, S. 1994. Expression of three somatostatin receptor subtypes in pituitary adenomas: evidence for preferential SSTR5 expression in the mammosomatotroph lineage. J. Clin. Endocrinol. Metab. 79:724-729.

93. Saveanu, A., et al. 2001. Bim-23244, a somatostatin receptor subtype 2 - and 5-selective analog with enhanced efficacy in suppressing growth hormone (GH) from octreotide-resistant human GH-secreting adenomas. J. Clin. Endocrinol. Metab. 86:140-145.

94. Ben-Shlomo, A., et al. 2005. Somatostatin receptor type 5 modulates somatostatin receptor type 2 regulation of adrenocorticotropin secretion. J. Biol. Chem. 280:24011-24021.

95. Ren, S.G., et al. 2003. Functional association of somatostatin receptor subtypes 2 and 5 in inhibiting human growth hormone secretion. J. Clin. Endocrinol. Metab. 88:4239-4245.

96. Grant, M., Alturaihi, H., Jaquet, P., Collier, B., and Kumar, U. 2008. Cell growth inhibition and functioning of human somatostatin receptor type 2 are modulated by receptor heterodimerization. $\mathrm{Mol}$. Endocrinol. 22:2278-2292.

97. Freda, P.U. 2002. Somatostatin analogs in acromegaly. J. Clin. Endocrinol. Metab. 87:3013-3018.

98. Murray, R.D., and Melmed, S. 2008. A critical analysis of clinically available somatostatin ana$\log$ formulations for therapy of acromegaly. J. Clin. Endocrinol. Metab. 93:2957-2968.

99. Vale, W., Vaughan, J., Yamamoto, G., Spiess, J., and Rivier, J. 1983. Effects of synthetic human pancreatic (tumor) GH releasing factor and somatostatin, triiodothyronine and dexamethasone on GH secretion in vitro. Endocrinology. 112:1553-1555.

100.Tannenbaum, G.S., and Ling, N. 1984. The interrelationship of growth hormone $(\mathrm{GH})$-releasing factor and somatostatin in generation of the ultradian rhythm of GH secretion. Endocrinology. 115:1952-1957.

101.Ferone, D., et al. 2008. Correlation of in vitro and in vivo somatotropic adenoma responsiveness to somatostatin analogs and dopamine agonists with immunohistochemical evaluation of somatostatin and dopamine receptors and electron microscopy. J. Clin. Endocrinol. Metab. 93:1412-1417.

102.Acunzo, J., et al. 2008. Somatostatin receptor sst2 decreases cell viability and hormonal hypersecretion and reverses octreotide resistance of human pituitary adenomas. Cancer Res. 68:10163-10170.
103.Ayuk, J., Stewart, S.E., Stewart, P.M., and Sheppard, M.C. 2002. Long-term safety and efficacy of depot long-acting somatostatin analogs for the treatment of acromegaly. J. Clin. Endocrinol. Metab. 87:4142-4146

104.Bevan, J.S., et al. 2002. Primary medical therapy for acromegaly: an open, prospective, multicenter study of the effects of subcutaneous and intramuscular slow-release octreotide on growth hormone, insulin-like growth factor-I, and tumor size. J. Clin. Endocrinol. Metab. 87:4554-4563.

105. Cozzi, R., et al. 2006. Primary treatment of acromegaly with octreotide LAR: a long-term (up to nine years) prospective study of its efficacy in the control of disease activity and tumor shrinkage. J. Clin. Endocrinol. Metab. 91:1397-1403.

106. Mercado, M., et al. 2007. A prospective, multicentre study to investigate the efficacy, safety and tolerability of octreotide LAR (long-acting repeatable octreotide) in the primary therapy of patients with acromegaly. Clin. Endocrinol. (Oxf). 66:859-868.

107. Maiza, J.C., et al. 2007. Long-term (up to 18 years) effects on GH/IGF-1 hypersecretion and tumour size of primary somatostatin analogue (SSTa) therapy in patients with $\mathrm{GH}$-secreting pituitary adenoma responsive to SSTa. Clin. Endocrinol. (Oxf). 67:282-289.

108.Sherlock, M., et al. 2009. Medical therapy in patients with acromegaly: predictors of response and comparison of efficacy of dopamine agonists and somatostatin analogues. J. Clin. Endocrinol. Metab. 94:1255-1263.

109.Carlsen, S.M., et al. 2008. Preoperative octreotide treatment in newly diagnosed acromegalic patients with macroadenomas increases cure short-term postoperative rates: a prospective, randomized trial. J. Clin. Endocrinol. Metab. 93:2984-2990.

110.Colao, A., et al. 2009. Octreotide LAR vs. surgery in newly diagnosed patients with acromegaly: randomized, open-label, multicentre study. Clin. Endocrinol. (Oxf). 70:757-768.

111.Karavitaki, N., et al. 2008. Surgical debulking of pituitary macroadenomas causing acromegaly improves control by lanreotide. Clin. Endocrinol. (Oxf). 68:970-975.

112.Murray, R.D., et al. 2004. Central and peripheral actions of somatostatin on the growth hormoneIGF-I axis. J. Clin. Invest. 114:349-356.

113. Pokrajac, A., Frystyk, J., Flyvbjerg, A., and Trainer, P.J. 2009. Pituitary-independent effect of octreotide on
IGF-I generation. Eur. J. Endocrinol. 160:543-548

114. Melmed, S., et al. 2005. A critical analysis of pituitary tumor shrinkage during primary medical therapy in acromegaly. J. Clin. Endocrinol. Metab. 90:4405-4410.

115. Mazziotti, G., et al. 2009. Effects of somatostatin analogs on glucose homeostasis: a metaanalysis of acromegaly studies. J. Clin. Endocrinol. Metab. 94:1500-1508.

116. Ben-Shlomo, A., and Melmed, S. 2007. Pasireotide-a somatostatin analog for the potential treatment of acromegaly, neuroendocrine tumors and Cushing's disease. IDrugs. 10:885-895.

117. van der Hoek, J., et al. 2004. A single-dose comparison of the acute effects between the new somatostatin analog SOM230 and octreotide in acromegalic patients. J. Clin. Endocrinol. Metab. 89:638-645.

118.Ren, S.G., et al. 2003. Suppression of rat and human growth hormone and prolactin secretion by a novel somatostatin/dopaminergic chimeric ligand. J. Clin. Endocrinol. Metab. 88:5414-5421.

119. Rocheville, M., et al. 2000. Receptors for dopamine and somatostatin: formation of hetero-oligomers with enhanced functional activity. Science. 288: $154-157$.

120. Chen, W.Y., Wight, D.C., Wagner, T.E., and Kopchick, J.J. 1990. Expression of a mutated bovine growth hormone gene suppresses growth of transgenic mice. Proc. Natl. Acad. Sci. U. S. A. 87:5061-5065.

121. Ross, R.J., et al. 2001. Binding and functional studies with the growth hormone receptor antagonist, B2036-PEG (pegvisomant), reveal effects of pegylation and evidence that it binds to a receptor dimer. J. Clin. Endocrinol. Metab. 86:1716-1723.

122.Trainer, P.J., et al. 2000. Treatment of acromegaly with the growth hormone-receptor antagonist pegvisomant. N. Engl.J. Med. 342:1171-1177.

123.Schreiber, I., et al. 2007. Treatment of acromegaly with the GH receptor antagonist pegvisomant in clinical practice: safety and efficacy evaluation from the German Pegvisomant Observational Study. Eur. J. Endocrinol. 156:75-82.

124.Carmichael, J.D., Bonert, V.S., Mirocha, J.M., and Melmed, S. 2009. The utility of oral glucose tolerance testing for diagnosis and assessment of treatment outcomes in 166 patients with acromegaly. J. Clin. Endocrinol. Metab. 94:523-527.

125.Resmini, E., et al. 2009. Computed tomography colonography in acromegaly. J. Clin. Endocrinol. Metab. 94:218-222. 